\title{
Eisen und Mangan.
}

\section{Ueber einige nene Doppelsalze,}

als phosphorsaures Amnoniak-Eisenoxydul, arseniksaures Ammoniak - Manganoxydul und paraphosphorsaures Natron - Ammoniak - Manganoxydul;

$$
\text { von }
$$

Dr. Fr. J. Otto in Braunschweig.

Die frähers Esotideckung des Verf. von einer, der phusphorsearen Ammoniak-Magnesia entsprechenden, Manganoxydulrerbindung *), fuhrte denselben zu analogen Verbinduugen der Pbosphorsăure wit dem Eisenoxydul und Ammoniak, der Arsenikeäure mit Manganoxydul und Ammonial, und eine, darch Natrongehalt sich unterzeheidende, Verbindung der Paraphospborsäure mit Manganoxydul und Ammonialk, von wolchen neuen Salzen er Darateilung und Eigenecbaften ausfiubrich angiebt, und die hier der Hauptsachs nach folgen sollen.

\section{Phosphorsaures Eisenoxydul-Ammoniak.}

Darstellung. Das Gelingen der Operation hängt rorzuglich davos ab, ein eisenuxydfreies Eisenoxydal anzuwenden, und so auch bei der Bawerkstelligung der Verbindung den Zutritt der Luft zu rerhüten. 14 Theile metallisches Eisen (eiserne Nägel) wurden in heifser Salzsiure gelöst, und diese suore Auflosung mit etwas schwefeligesurem Ammoniath versetzt. 100 Thl. hrgstullisirtes, phosphorseares $\mathrm{Na}$ tron wurden in Wasser gelöst, und diese L.ösang, zar Verjagang des absorbirten Sauerstuffis, erbitzt.

Zu dieser letztern, noch heifsen Flüssigheit wurde nun

") 8. diese Anmalen, Bd. VILL. \&. in3. 
die Eisenoxydulauflosung gegossen, wo sogleich ein vollkommen weifser Niederschlag ron phosphorsaurem Eisenoxydal entstand, dann Ammoniak in geringem Deberschusse zagogeben, die Flasche fest zugekorkt, geschüttelt und der Rohe überlassen. Es braucht wohl kaum noch bemerkt 24 werdes, dafs von dem möglichst schrellen Zusammengeben der drei Flüssigheiten das Gelingen der Operation ganz vorzüglich abbängig ist.

Gewöhnlich nach einigen Miruten schon, oft aber anch viel später, nimmt der anfangs hydratische, weifse Niederschlag eine lirystallinische Gestalt an, was man leicht an den opiegelnden Flächen der zarten Blättchen beim Bewegen des Gefäfses erkennt, and auch daran, dafs derselbe sich jetzt schnell in der Flüssigkeit zo Boden senkt. Die Bildung des Doppelsalyes ist dann vollendel, und man hat oun rom Saverstoff der atmosphärischen Luft nichts mehr zu fürchten.

Bisweilen geschieht es, dafs der Niederschjag nicht die ausgezeichneten krystallinischen Blättchen darsteilt, sondern mehr bydratisch bleibt; der Vorf. hat dann dieselben noch erhalten bönnen, wenn er die Flüssigheit wieder erhitzte, auch wohl etwas Salmiakaufiösung zuiügte.

Nach der Frkaitung tronut man das Doppelsale durchs Filter von der Flüssiglıeit, unủ will man es rechbt schŏn erhaiten, so schlemmt man das teine, weniger bryotallinisehe ab, und bringt so nur die gröfsern Blättchen auf Filter. Nan wäscht mit gelinchtem destillirtem Wasser

Eigenschaften. Das Filter überzieht dieses Salz in feuchten Zustande mit. einer metallisch glänzenden Decke. Nach dem Trochnen erscheint es als grünlichweirse, sehr leichte Blättchen, die, auf die Haut eingerieben, diese gleichsam versilbern.

An der Luft ist es bei gewöhnlicher Temperatur anreronderlich; erbitzt entiöfst es Wasser und Ammoniak, and es 
bleibt, Anfengs grünliches, phosphortaures Eisenoxydul, stärLer erhitzt, gelblichweifses phosphoreanres Eisenoxyd. Im Wasser, selbst hoifsen, und in Alkohol ist es unlöslich.

Feucht ist es in verdünnter Säure leicht, trocken erst in concentrirter Säure löslich.

Aetzhalilange entwichelt aus dem Salze Ammonials, nnd entzieht ihm beim Kochen die Phosphorsäure, es bleibt gränlichbraunes Eisenoxydoxydul von der Gestalt des Doppelsalzes, welches beim Erhitzen zu sehr schōn rothem Eisenozyd wird, an dem man ebenfalls noch die leystalliniache Struktur des Salzes erkennen kann.

In 100 Th. fand der Verf. dieses Salz zusammengecotat abs:

$$
\begin{array}{lr}
\text { Phosphorsaiure } & 39,778 \\
\text { Eisevoxydul } & 38,222 \\
\text { Ammoniak . } \quad 8,770 \\
\text { Wasser . . } \quad 14,230 \\
\hline 100,000
\end{array}
$$

was 1 M. G. Phosphorsäure, , M. G. Eisenoxydul, 1/2 M. G. Wasser entspricht.

$$
\text { Arseniksaures Ammoniak-Manganoxydul. }
$$

Darstellung. Za einer Aufösung ron Arsenilsäure oder arseniksanrem Ammonial bringt man eine Aufösong ron Manganchlorid und Ammoniak. Das Vermienhen der Flüssigleit geschieht wieder am besten in der Wärme. Auch hier scheidet sich Anfanga arseniksaures Manganoxydul als bydratischer Niederschlag aus, der sich aber nach einiger Zeit in das hörnig-krystallinische Doppelsalz amändert. Das Salz wird mit gekochtem Waser ausgewaschen.

Iigenschafter. Getrocknet stellt es entweder ein weifes, krystallinisches Pulver dar, welches einen Strich ins Rotbe zcigt, oder es erscheint in rothlichen, sehr lileinen Krystallen. 
An der Luft ist es bei gewöbniicher Temperntar unveränderlich. In der Hize ontlälst es Wasser und Ammonial, und arsenihsaures Munganoxydul bleibt zurück. In Wassor and Allohol ist os unlöslich; ron verdünnten Säuren wird es leicht gelöst. Fixe, ätzende Alkalien wirken wie af die ahnlichen Salze.

Die Analyse, roransgesetzt, dals boim Erhitzen elnfacharsenikseures Mangunoxydul bieibt,

\begin{tabular}{|c|c|}
\hline Arseniksüure & - 36,886 \\
\hline Anumonial. & $5,6,8$ \\
\hline Waseer & - 3h,bu. \\
\hline
\end{tabular}

oder , M. G. Arseniksüure, M. G. Manganoxydal, $1 / 3$ M. G. Ammonish und $6 \mathrm{M}$. G. Wasser.

\section{Paraphosphorsaures Natron-Ammoniak-Mangan- oxydul.}

Darstellung. Eine Auflösung ron frisch geglihtem, phoaphorsaurem Natron in Wasser, wird mit einer wässerigen Auflösung ron Manganchlorür and Ammonisb rersetzt: anfangs bildet sich ein brdratischor Niederschlag, der sehr bald sich zi einem hrystalinischen umwandeit, welches das in Rede stehende Soiz ist.

Eigensckaften. Getrochnet erstiseint es vollhomnten weifo, hochstens schwach ins Rothliche spielend. Hsi geswöhnlichar Temperator ist anveränderlich. In Wasser und Alkohol löst es sich nicht. In Sāuren, selhst sehr verdünuten; ist es aber leicht lisslich. Mit concentrirtcr Salpelersäure gekocht, scheidet sich Manganäberoxyd ans. Gegen fixe, ëtzendo ALunitien verhält es sich, we die rorhergehenden Ioppelsalze; ebenso beim Erbitzen, jedoch bleibt gine grauwtifse, binssteinurtige hasse zurisk, die sauez reagirt. 
Bereitung des Quechsilberjodids und Quechsiberjodirs. 203.

Die Analyse hatte dom Verf. grofee Schwierigkeiten dedurch veranlafst, dafs er anfangs hein Natron darin vermu thete. Nach 3 Analysen bält der Verf. zusammengosetzt aus :

$$
\begin{aligned}
& \text { Manganoxydul - 22,37 } \\
& \text { Natron . . . } \mathbf{7 , 9 0} \\
& \text { Ammoniah . . } \mathbf{4 , 9 0} \\
& \text { Phosphorsaure . 4 4h,37 } \\
& \frac{\text { Wasser ... . 20,46 }}{100,00 .}
\end{aligned}
$$

oder aus , M. G. Manganoxydul, 1/2 M. G. Natron, 1/2 M. G.

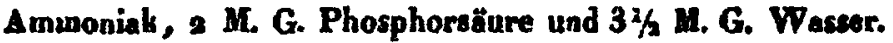

(Jourssal fär preht. Chemio, Bd. I. S. 409)

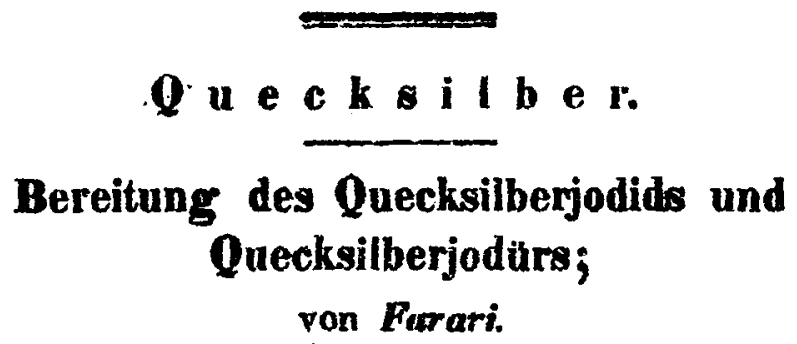

Auf pulverisirtes schwefblsaures Quecksilberoxfd giefst man so lange eine Lösang von Jodkslium in 3 Theilen Wasser unter beatīndigen Umrühren, bis die Bildung von schwefelesurem Hali und Quecksilberjodid rollendet ist; darch Aussüfsen trennt man letzteres vom schwefelasuren Kali, worauf os getrocknet wird. Fur die Darstallung des Quecksilberjodürs hat man vorher das schwefolsaure Quectsilberoxyd mit $2 / 3$ seines Gewichts metallischen Quechsilbers innig zusammen zu reiben, und dann, wie vorhin, za verfabren.

(Gas, eclett. di farm. chim. Ser. II. p. 9.) 